\title{
Prediction for Magnesium Alloy Rolling Force Based on Quantitative Study of Contact Friction
}

\author{
Jia Weitao ${ }^{1,2}, \quad$ Ma Lifeng ${ }^{1}, \quad$ Tang Yan $^{2}, \quad$ Le Qichi $^{2}, \quad$ Huang Zhiquan ${ }^{1}, \quad$ Lin Jinbao ${ }^{1}$ \\ ${ }^{1}$ Shanxi Provincial Key Laboratory of Metallurgical Equipment Design and Technology, Taiyuan University of Science and Technology, \\ Taiyuan 030024, China; ${ }^{2}$ Key Laboratory of Electromagnetic Processing of Materials, Ministry of Education, Northeastern University, \\ Shenyang 110819, China
}

\begin{abstract}
The magnesium alloy hot rolling process was investigated. A method was proposed to determine the friction factor in the process through the comparative analysis of finite element analysis result and experimental data. Mathematical model for solving the friction factor was established, combining with multi-parameters of the rolling process: rolling temperature, rolling speed and reduction rate. Based on calculation model of rolling force and temperature distribution along the contact region in hot rolling of AZ31B magnesium alloy in previous researches, to the rolling force prediction model was optimized and reconstructed considering the normal pressure and friction stress comprehensively. The contact friction stress and its influence on rolling force with an approximate percentage of $4.36 \%$ was defined.
\end{abstract}

Key words: rolling process; friction factor; rolling force; normal pressure; friction stress

Magnesium alloy sheet is easy to produce defects in rolling process, including edge crack and surface microcrack, etc. It is well known that the prediction accuracy of mechanical model of rolling force directly determines the yield in magnesium alloy sheet and the control precision of the plate flatness and thickness. Nowadays, rolling force calculation theory applied in the preparation of magnesium alloy sheet is still not perfect, which mainly depends on fitting analysis and regression calculation versus a large number of field data, resulting in the limitation for magnesium alloy rolling production ${ }^{[1]}$. Ignoring small deformation of rolling mill system, the interfacial deformation is the source of rolling force, which mainly consists of unit normal pressure and unit friction stress. Lenard and Barbulovic-Nad proposed that at high normal pressures the physical meaning of friction was reduced ${ }^{[2]}$. In addition, the friction factor in steel strip rolling is so small that rolling force prediction usually neglects its effect. However, magnesium alloy is a particularly soft material with poor oxidation resistance and high temperature sensitivity ${ }^{[3]}$. Compared with steel strip, the effect of friction of magnesium alloy on rolling force cannot be ignored. Then quantitative research of the effect of contact friction can improve the forecasting precision of rolling force of magnesium alloy. Nowadays, there are many experimental methods to measure rolling friction factor $^{[4]}$; however, to define it in hot rolling process of $\mathrm{Mg}$ alloys they all have limitations. Based on the prediction for AZ31B rolling force in previous study ${ }^{[5]}$, forecasting accuracy was improved by accurately predicting temperature distribution in the deformation zone in a subsequent study $^{[6]}$. Considering the limitations of experimental methods, a new method was proposed to determine the friction factor in magnesium alloy rolling process, which combined the numerical simulation and physical tests for comparative analysis and differs much from the traditional methods (well applied in the study previous ${ }^{[7]}$ ). Finally, the effect of contact friction on rolling 
force was quantified and the rolling force prediction model coupled process parameters were established with a high prediction accuracy, which can provide a reliable principle basis for rolling of magnesium sheet.

\section{Experiment}

As-cast AZ31B magnesium alloy (Table 1) came from a company in China prepared by the low frequency electromagnetic and continuous casting technology.

Rolling mill adopted was automatic controlled two-high mill, the diameter of roller was $320 \mathrm{~mm}$ and magnesium plate size was $150 \mathrm{~mm} \times 150 \mathrm{~mm} \times 7 \mathrm{~mm}$. Roller heating covers designed independently were adopted for temperature compensation (limitation was $220{ }^{\circ} \mathrm{C}$, Fig. 1 ). Roller temperature was controlled in a range from $120^{\circ} \mathrm{C}$ to $150{ }^{\circ} \mathrm{C}$ in the rolling process without lubrication.

Rolling temperature was tracked and recorded by infrared temperature scanner of MP150 series from Raytek Company of USA (Fig.1). Rolling time was detected by VCGC-P100BAC camera with flash memory and recorded at $100 \mathrm{frame} / \mathrm{s}$. Then Adobe Premiere Pro CS4 software was used to catch starting rolling point $t_{0}$ and ending rolling point $t_{1}$ to define the rolling time $t$ (Fig.2).

Rolling test schemes and rolling results are listed in Table 2. Arrhennius flow stress model with a high forecasting precision was established previously, and based on true stress-strain data ${ }^{[8]}$. The model was imported into material library of DEFORM-3D to construct as-cast AZ31B magnesium alloy for finite element analysis. Both sheet and roller thermal physical parameters were inspected in accuracy for setting simulation parameters in DEFORM-3D: AZ31B density $1778 \mathrm{~kg} / \mathrm{m}^{3}$, roller density

Table 1 Chemical elements contents of the sheet (wt\%)

\begin{tabular}{cccccccc}
\hline $\mathrm{Al}$ & $\mathrm{Zn}$ & $\mathrm{Mn}$ & $\mathrm{Fe}$ & $\mathrm{Si}$ & $\mathrm{Cu}$ & $\mathrm{Ni}$ & $\mathrm{Mg}$ \\
\hline 3.37 & 0.86 & 0.29 & 0.04 & 0.1 & 0.0015 & 0.0047 & Bal. \\
\hline
\end{tabular}
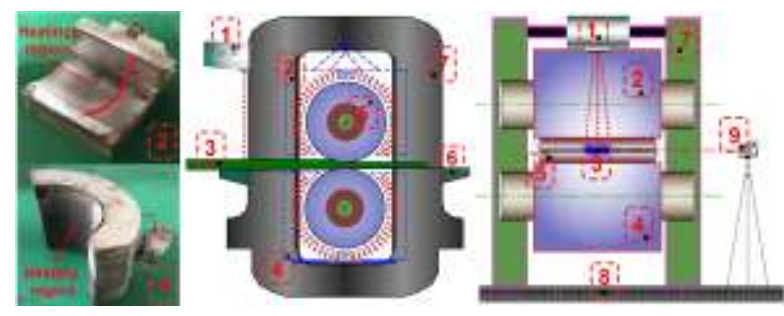

1 infrared thermometer; 2 upper heating cover; 3 AZ31B magnesium alloy plate; 4 lower heating cover; 5 roller; 6 guide plate; 7 rolling mill; 8 ground; 9 camera

Fig. 1 Installation of infrared thermometer, heating covers and rolling time detection

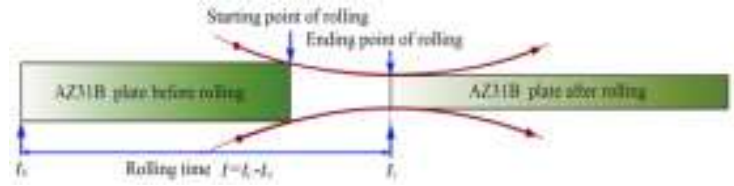

Fig. 2 Definition of rolling time

$7800 \mathrm{~kg} / \mathrm{m}^{3}$, roller elastic modulus $215 \mathrm{GPa}$ and others are listed in Table 3.

\section{Results and Discussion}

\subsection{Main effect of unit normal pressure}

Fig. 3 shows schematic diagram of the rolled plate.

Considering the difference of heat-transfer mechanism and deformation parameters between backward slip zone and forward slip zone, a previous predicting model for characterizing the effect of unit normal pressure on rolling force was established by a method separating deformation zone to solve then modeling overall (Eq. (1) $)^{[5]}$.

$$
P_{\sigma}=\bar{p}_{1} \bar{B}_{1} L_{c 1}+\bar{p}_{2} \bar{B}_{2} L_{c 2}
$$

where, $\overline{p_{1}}$ and $\overline{p_{2}}$ is average unit normal pressure distributed along the contact arc in backward slip and forward slip zone, and $\bar{B}_{1}$ and $\bar{B}_{2}$ is average interfacial width in backward slip and forward slip zone, respectively. According to the geometric relations in Fig.3, $L_{c 1}, L_{c 2}$, $\bar{B}_{1}$ and $\bar{B}_{2}$ can be solved.

We considered the characteristic of magnesium alloy in hot rolling that the sticking phenomenon existed in the contact arc, a modified R. B. Sims unit pressure calculation for $\overline{p_{1}}$ and $\overline{p_{2}}$ (in previous study ${ }^{[5]}$ ) was used for discrete solution. To increase the calculation accuracy of $\overline{p_{1}}$ and $\overline{p_{2}}$, previous temperature estimation was replaced with model solution in later study ${ }^{[6]}$. Comparison of experimental, pre- and post-calculated rolling force values are shown in Fig. 4.

Temperature estimated method cannot characterize the complex exchange between thermal conductance and deformation heat, which leads to that temperature calculated is less than experimental value. Then the hardening effect of low temperature is exaggerated, leading to that rolling force calculated is larger than experimental value. Temperature distribution model in the study ${ }^{[6]}$ precisely calculated the temperature distribution in rolling deformation zone, therefore, rolling force prediction accuracy would be increased. But considering the unit normal pressure only while establishing the rolling force model above, all experimental values appear to be higher than calculated values by Eq. (1). Due to the direct contact between the roller and workpiece, distribution of friction in forward slip zone and backward slip zone can affect rolling pressure directly. According to the minimum flow 
Table 2 Experimental scheme of hot rolling

\begin{tabular}{ccccccccc}
\hline Scheme & $T_{0} /{ }^{\circ} \mathrm{C}$ & $T_{1} /{ }^{\circ} \mathrm{C}$ & $\varepsilon_{0} / \%$ & $\varepsilon_{1} / \%$ & $v / \mathrm{m} \cdot \mathrm{s}^{-1}$ & $P_{\mathrm{e}} / \mathrm{t}$ & $t_{\mathrm{e}} / \mathrm{s}$ \\
\hline 1 & 250 & 248.7 & 30 & 32.38 & 0.5 & 49.31 & 0.37 \\
2 & 300 & 302.5 & 30 & 31.95 & 0.5 & 42.81 & 0.36 \\
3 & 350 & 355.8 & 30 & 32.78 & 0.5 & 39.53 & 0.36 \\
4 & 400 & 411.4 & 30 & 31.02 & 0.5 & 34.52 & 0.35 \\
5 & 450 & 457.4 & 30 & 30.35 & 0.5 & 28.60 & 0.34 \\
6 & 350 & 354.0 & 20 & 18.81 & 0.5 & 29.54 & 0.32 \\
7 & 350 & 348.2 & 40 & 38.67 & 0.5 & 47.25 & 0.39 \\
8 & 350 & 351.8 & 30 & 29.52 & 0.1 & 39.89 & 39.41 & 1.80 \\
9 & 350 & 352.5 & 30 & 30.52 & 0.8 & & 0.22 \\
\hline
\end{tabular}

Note: $T_{0}$ and $\varepsilon_{0}$ is theoretical design temperature and reduction rate, respectively, $T_{1}$ and $\varepsilon_{1}$ are actual test value, $v$ is rolling speed, $P_{\mathrm{e}}$ is rolling force, $t_{\mathrm{e}}$ is rolling time

Table 3 Thermal physical parameters of sheet and roller for AZ31B plate and roller

\begin{tabular}{rccccccc}
\hline$T /{ }^{\circ} \mathrm{C}$ & $C_{\mathrm{SP}} / \mathrm{kJ} \cdot\left(\mathrm{kg} \cdot{ }^{\circ} \mathrm{C}\right)^{-1}$ & $C_{\mathrm{SR}} / \mathrm{kJ} \cdot\left(\mathrm{kg} \cdot{ }^{\circ} \mathrm{C}\right)^{-1}$ & $C_{\mathrm{TP}} / \mathrm{W} \cdot\left(\mathrm{m} \cdot{ }^{\circ} \mathrm{C}\right)^{-1}$ & $C_{\mathrm{TR}} / \mathrm{W} \cdot\left(\mathrm{m} \cdot{ }^{\circ} \mathrm{C}\right)^{-1}$ & & $E / \mathrm{MPa}$ & $\alpha / \times 10^{-5} \cdot{ }^{\circ} \mathrm{C}^{-1}$ \\
\hline 25 & 1.04 & 0.452 & 96.487 & 56.903 & 45.093 & 2.601 \\
50 & 1.11 & 0.451 & 97.751 & 56.956 & 45.093 & 2.614 \\
100 & 1.11 & 0.458 & 101.022 & 56.903 & 45.205 & 2.643 \\
150 & 1.14 & 0.497 & 102.955 & 55.284 & 42.305 & 2.674 \\
200 & 1.17 & 0.534 & 104.888 & 53.508 & 39.740 & 2.706 \\
250 & 1.19 & 0.55 & 106.896 & 51.470 & 34.721 & 2.744 \\
300 & 1.21 & 0.568 & 109.126 & 49.381 & 29.368 & 2.790 \\
350 & 1.24 & 0.587 & 110.911 & 47.552 & 27.249 & 2.804 \\
400 & 1.26 & 0.611 & 112.993 & 45.202 & 24.796 & 2.820 \\
450 & 1.26 & 0.621 & 114.301 & 44.811 & 24.102 & 2.831 \\
\hline
\end{tabular}

Note: $T$-temperature, $C_{\mathrm{SP}}$-specific heat capacity, $C_{\mathrm{SR}}$-specific heat capacity of roller, $C_{\mathrm{TP}}$-thermal conductivity, $C_{\mathrm{TR}}$-thermal conductivity of roller, $E$-elastic modulus, $\alpha$-expansion coefficient

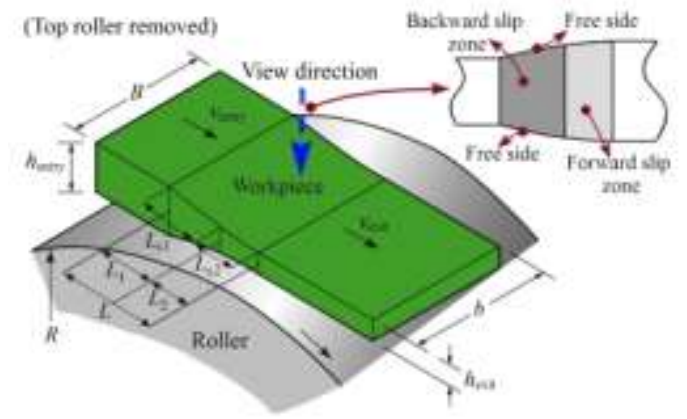

$L_{\mathrm{c} 1}$ and $L_{\mathrm{c} 2}$ is contact arc length of rolled plate in backward slip and forward slip zone, $L_{1}$ and $L_{2}$ is the related vertical projection, respectively, $h_{\text {entry }}$ and $h_{\text {exit }}$ is the thickness before and after rolling, $R$ is the roller radius, $L$ is projected contact length

Fig. 3 Schematic diagram of the rolled plate resistance in metal flow, as the friction factor is increased the spread increases. А. И. ЦеПИКОВ model ( Eq. (2)), Б. П. БахТИНОВ model (see Eq. (3)), С. И. ГУбКИН model

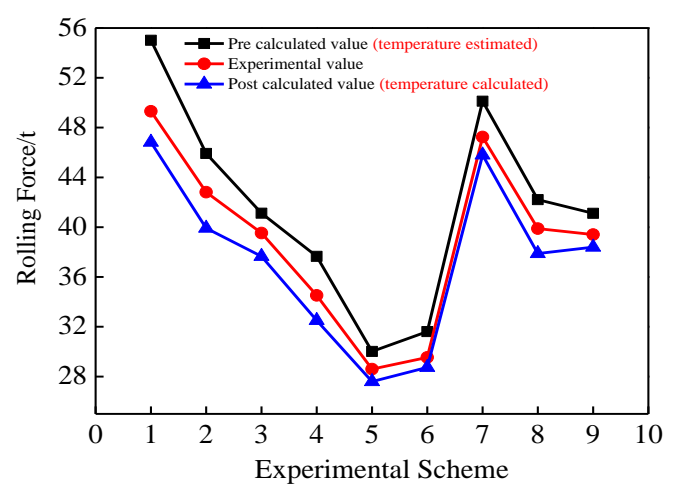

Fig. 4 Calculated and experimental rolling force values 
(Eq. (4)) are commonly used for spread calculation ${ }^{[9]}$, which show that contact-friction factor influences primary effect of unit normal pressure on rolling force by affecting width spread $\Delta b$.

$$
\begin{aligned}
& \Delta b=C \Delta h\left(2 \sqrt{\frac{R}{\Delta h}}-\frac{1}{\mu}\right)\left[0.138\left(\frac{\Delta h}{h_{\text {entry }}}\right)^{2}+0.328 \frac{\Delta h}{h_{\text {entry }}}\right] \\
& \Delta b=1.15\left(\Delta h / 2 h_{\text {entry }}\right)(\sqrt{R \Delta h}-\Delta h / 2 \mu) \\
& \Delta b=\left(1+\Delta h / h_{\text {entry }}\right)(\mu \sqrt{R \Delta h}-\Delta h / 2)\left(\Delta h / h_{\text {entry }}\right)
\end{aligned}
$$

where, $\Delta b=b-B, C$ is ratio coefficient. $\Delta h=h_{\text {entry }}-h_{\text {exit }}, R$ is roller radius, $\mu$ is factor of friction(Fig. 3).

\subsection{Quantified effect of contact friction}

А. И. ЦеПикОв has classified rolling friction on the basis of $L / \bar{h}$, where $\bar{h}$ is the average thickness in deformation zone $^{[4]}$. Many literatures showed that small reduction rate and multi-pass hot rolling could reduce defects and improve mechanical properties of magnesium alloy plate. In view of small reduction rate, hot rolling friction of magnesium alloy belongs to $L / \bar{h}=2 \sim 5^{[4]}$. Distribution of contact friction and unit pressure in deformation zone is shown in Fig. 5.

Neural point is a demarcation point in deformation zone (Fig.5). Contact friction distributed in the two respective zones is opposite, so rolling force is weakened in forward slip zone but strengthened in backward slip zone. Rolling force on workpiece mainly distributes in the backward slip zone. Then the strengthening effect of contact friction is dominant mostly, resulting in rolling force increasing. Taking scheme 3 (Table 2) as an example, statistical rolling force and rolling time of simulation are shown in Fig. 6 .

Fig.6 shows that rolling force has obviously positive correlation with friction factor. Increase of friction stress will reduce metal flow velocity with respect to the roller and the degree of interfacial slipping, which shorten the rolling time. According to functional relationship between rolling force, rolling time and friction factor, experimental rolling time and rolling force were compared with simulation under conditions of different friction factors. Then the friction factor in process will be determined by

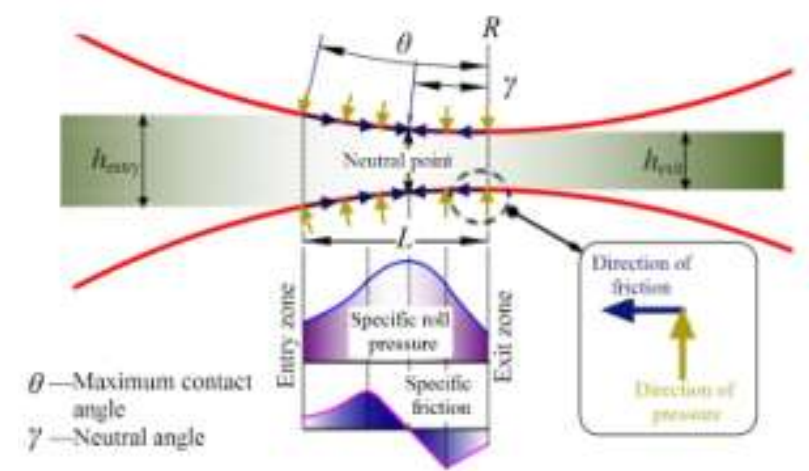

Fig.5 Contact-friction in deformation and unit pressure distribution setting a similar threshold between experimental and calculated values. Based on this analysis principle, for experiment schemes (Table 2), friction factor is conducted to the coupled thermo-mechanical simulation at the step size of $0.02(0.2,0.22, \ldots 0.5)$. The relationship of rolling time and rolling force on friction factor are shown as Fig. 7 and Fig. 8.

Numerical simulation results were fitted by the method of least squares for predicting mathematical relationship under a wide range of process conditions accurately. Among them, rolling force was fitted into a linear equation and as a micro variable, rolling time was fitted into a cubic function (Table 4). Similarity $\xi$ coupled rolling time and rolling force was proposed to search experimental friction factor:

$$
\xi=f(\mu)=\left|P-P_{\mathrm{e}}\right| / P_{\mathrm{e}}+\left|t-t_{\mathrm{e}}\right| / t_{\mathrm{e}}
$$

where, $P(\mathrm{t})$ and $t(\mathrm{~s})$ is simulated rolling force and rolling time, respectively, of each scheme in Table 2.

Take equations in Table 4 and experimental force and time values into Eq. (5) and draw curves of $\xi=f(\mu)$ (Fig.9) in plane right-angle coordinate. For defining similarity threshold in this study, friction factor $\mu$ of experimental scheme 3 was measured with the forward slip method. The experimental friction factor $\mu$ was taken into fitting equations

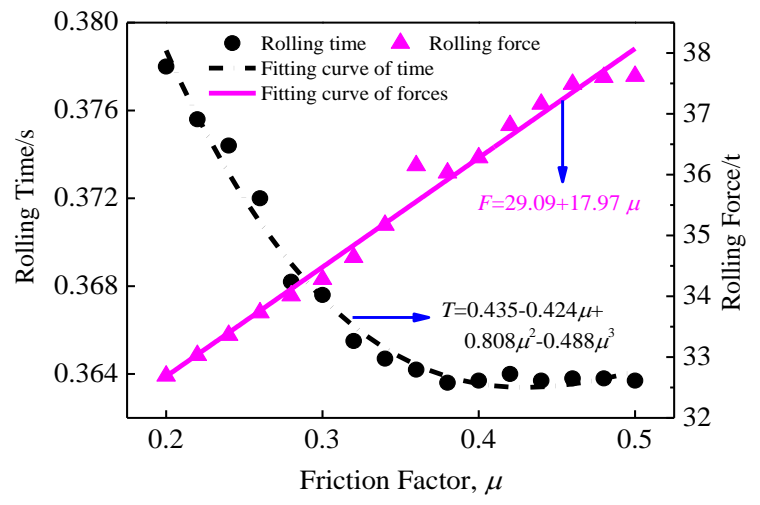

Fig.6 Rolling force and rolling time corresponding to different friction factor of scheme 3

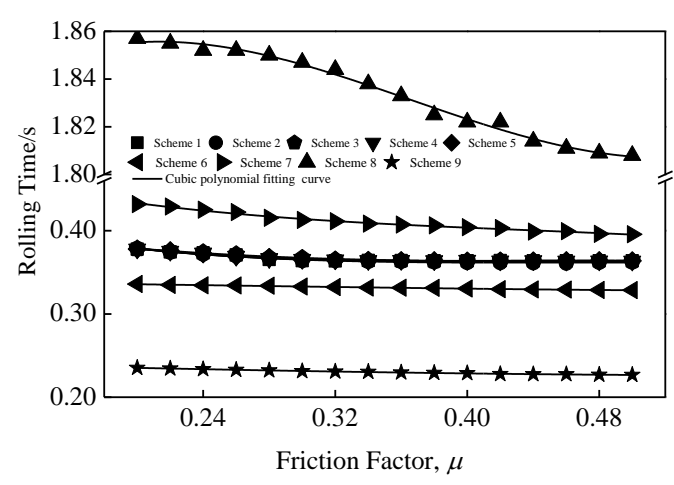

Fig. 7 Relationship between rolling time and friction factor 
Table 4 Rolling force and rolling time fitting results about friction factor

\begin{tabular}{cccccc}
\hline \multirow{2}{*}{ Scheme } & \multicolumn{2}{c}{ Rolling force fitting about friction factor } & & \multicolumn{2}{c}{ Rolling time fitting about friction factor } \\
\cline { 2 - 3 } \cline { 5 - 6 } & Equation & Adj. $R$-Square & & $t=-1.527 \cdot \mu^{3}+1.936 \cdot \mu^{2}-0.81 \cdot \mu+0.475$ & Adj. $R$-Square \\
\hline 1 & $P=26.27 \cdot \mu+38.8$ & 0.98961 & & & 0.94636 \\
2 & $P=23.17 \cdot \mu+33.61$ & 0.98796 & & $t=-1.044 \cdot \mu^{3}+1.428 \cdot \mu^{2}-0.648 \cdot \mu+0.459$ & 0.98559 \\
3 & $P=17.97 \cdot \mu+29.09$ & 0.98194 & & $t=-0.488 \cdot \mu^{3}+0.808 \cdot \mu^{2}-0.424 \cdot \mu+0.435$ & 0.98109 \\
4 & $P=16.4 \cdot \mu+25.36$ & 0.99472 & & $t=-1.48 \cdot \mu^{3}+1.858 \cdot \mu^{2}-0.775 \cdot \mu+0.471$ & 0.98298 \\
5 & $P=14.19 \cdot \mu+20.77$ & 0.99526 & & $t=-1.21 \cdot \mu^{3}+1.6 \cdot \mu^{2}-0.697 \cdot \mu+0.464$ & 0.99055 \\
6 & $P=11.56 \cdot \mu+24.07$ & 0.98586 & & $t=0.075 \cdot \mu^{3}-0.058 \cdot \mu^{2}-0.012 \cdot \mu+0.34$ & 0.98877 \\
7 & $P=27.65 \cdot \mu+31.61$ & 0.99403 & & $t=-1.037 \cdot \mu^{3}+1.354 \cdot \mu^{2}-0.669 \cdot \mu+0.521$ & 0.98852 \\
8 & $P=19.99 \cdot \mu+30.0$ & 0.98633 & & $t=3.43 \cdot \mu^{3}-3.762 \cdot \mu^{2}+1.136 \cdot \mu+1.751$ & 0.99026 \\
9 & $P=18.35 \cdot \mu+29.23$ & 0.97339 & & $t=0.04 \cdot \mu^{3}+0.006 \cdot \mu^{2}-0.048 \cdot \mu+0.244$ & 0.99460 \\
\hline
\end{tabular}

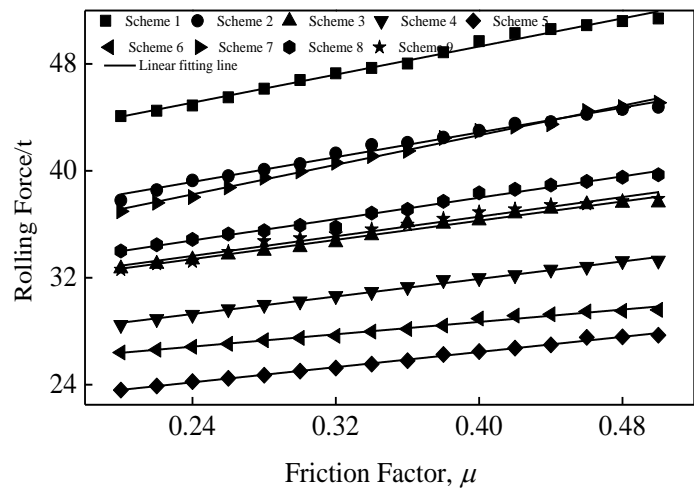

Fig. 8 Relationship between rolling force and friction factor

in Table 4 to calculate $P$ and $t . P_{\mathrm{e}}$ and $t_{\mathrm{e}}$ were obtained from the experiment. Finally, $P_{\mathrm{e}}, t_{\mathrm{e}}, P$ and $t$ were taken into Eq. (5) to solve similar threshold which was approximate 0.1 . Searching the $\xi=0.1$ points in Fig. 9, experimental friction factors could be obtained and listed in Table 5 .

Friction factors obtained were conducted to numerical simulation and damage analysis coupled thermo-mechanical again. Taking scheme 1 as an example, the comparison between experimental and simulation results is shown in Fig. 10 and statistical results are shown in Fig.11.

Measurement positions in Fig. 11 were marked corresponding to the position of measured values in Fig. 10. Average absolute relative error $\left(R_{\mathrm{AAE}}\right)$ was used to evaluate the experimental results and numerical simulation results:

$$
R_{\mathrm{AAE}}=\frac{1}{n} \sum_{i=1}^{n}\left(\left|Q_{i}-q_{i}\right| / Q\right)_{i} \times 100 \%
$$

where $Q_{i}$ is experimental value, $q_{i}$ is simulated value.

From Fig. 10 and Fig. 11, the simulation is similar to the experimental results: $R_{\mathrm{AAE}}=4 \%$ for the defect region length, $5.220 \%$ for the maximum edge defect length, and $10.02 \%$ for the average edge defect length. Due to the spread calculation theory, in the section 2.1 , friction factor $\mu$ directly determines the calculation accuracy of width spread $\Delta b$ (Eqs. (2), (3) and (4)). The average relative error of $\Delta b$

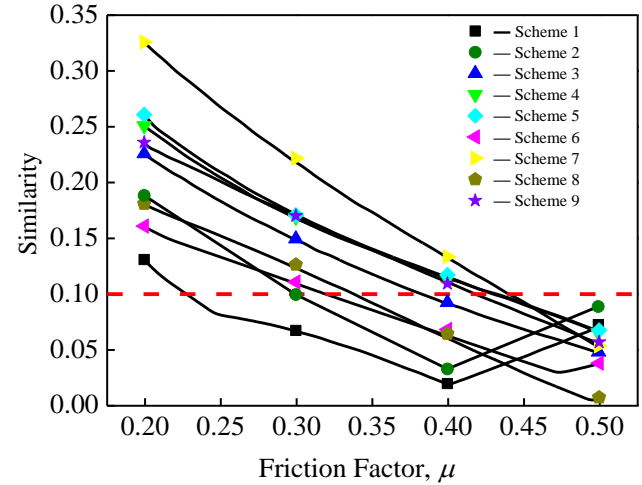

Fig.9 Functional curves of similarity of schemes in Table 2

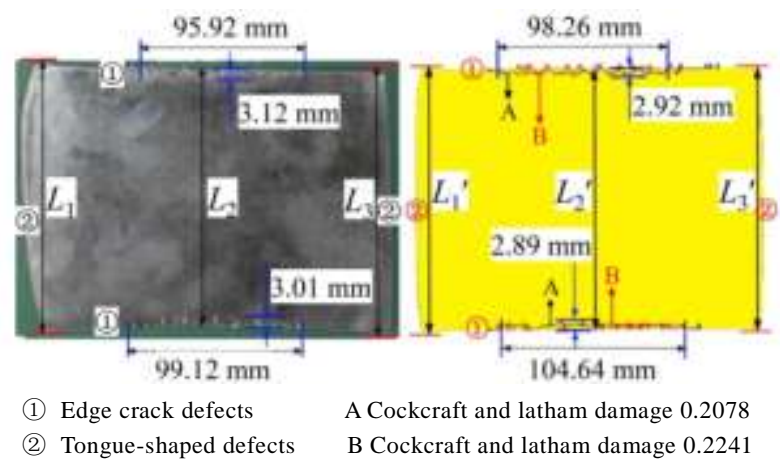

Fig. 10 Comparison between experimental and simulation results

can be calculated by Eq. (7):

$$
\psi=\left|\frac{L_{1}{ }^{\prime}-L_{1}+L_{2}{ }^{\prime}-L_{2}+L_{3}{ }^{\prime}-L_{3}}{L_{1}+L_{2}+L_{3}-450}\right| \times 100 \%
$$

where $L_{1}, L_{2}, L_{3}, L_{1}^{\prime}, L_{2}^{\prime}, L_{3}^{\prime}$ were marked in Fig. 10 .

Calculation of Eq. (7) for Scheme 1 is $4.05 \%$, for other scheme is $5.21 \%$ (Sch. 2), 6.23\% (Sch. 3), 4.01\% (Sch. 4), $3.98 \%$ (Sch. 5), 6.44\% (Sch. 6), 5.64\% (Sch. 7), 7.01\% (Sch. 8 ), and $6.04 \%$ (Sch.9). In view of the average relative error is in the range of the allowable error, friction factors listed in Table 5 can be considered as relatively accurate values. 


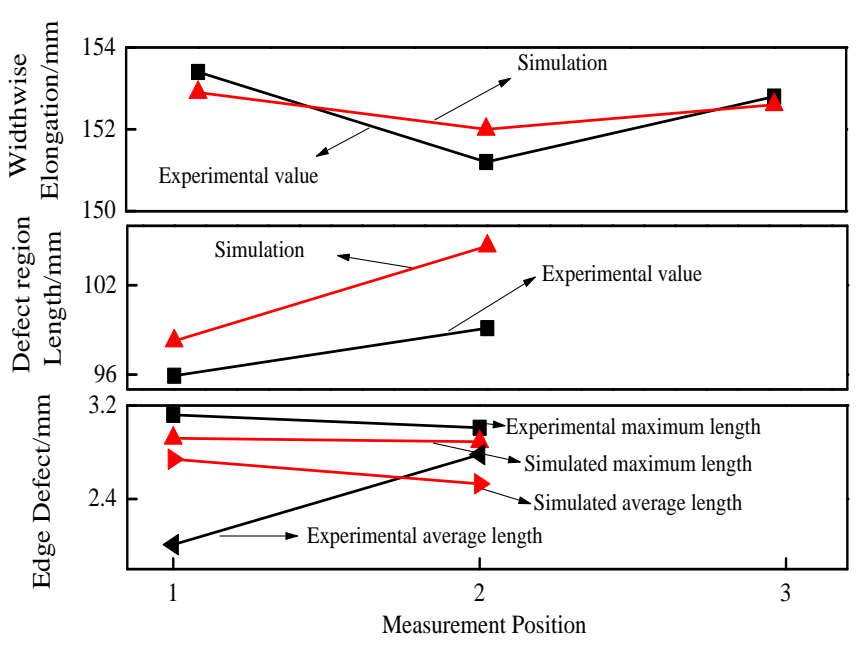

Fig.11 Statistical experimental results and simulation of scheme 1

Table 5 Friction factor $(\mu)$ of scheme 1 9

\begin{tabular}{ccccccccc}
\hline 1 & 2 & 3 & 4 & 5 & 6 & 7 & 8 & 9 \\
\hline 0.228 & 0.3073 & 0.3828 & 0.4308 & 0.4332 & 0.319 & 0.4412 & 0.3372 & 0.4197
\end{tabular}

Then, friction factors in Table 5 were fitted by the method of least squares on rolling process parameters for predicting mathematical relation under temperature $250 \sim 450{ }^{\circ} \mathrm{C}$, rolling reduction $20 \% \sim 40 \%$ and rolling velocity $0.1 \sim 0.8$ $\mathrm{m} / \mathrm{s}$ (see Eq. (8)). Fitting accuracy of the model is shown in Table 6 .

$$
\mu=-127.0171 / T_{1}+2.5210 \varepsilon_{1}^{3}+0.1441 v^{3}+0.6350
$$

\subsection{Relationship between friction and rolling pressure}

Because of the rolling pressure, the forces distribute along the contact arc between rollers and workpiece. Alexander (1972) established a mathematical model on the basis of the static equilibrium of the forces in a slab in the rolling deformation zone ${ }^{[10]}$ (Fig. 12).

$$
\mathrm{d}\left(\sigma_{x} h_{x}\right) / \mathrm{d} x+p \mathrm{~d} h_{x} / \mathrm{d} x \mp 2 \tau=0
$$

The dependent variables of equation were marked in Fig.12, where $p$ is rolling pressure, $x$ is an independent variable, indicating the distance in the direction of rolling measured from the line connecting two roller centers, $h_{x}$ is the strip thickness whose distance is $x$ from the exit, $\tau$ is the interfacial shear stress, $\tau=\mu p, \sigma_{x}$ is the stress in the rolling direction, and the $\mp$ sign designates that Eq.(9)

Table 6 Accuracy of contact-friction factor fitting model

\begin{tabular}{cc}
\hline Parameters & Value \\
\hline Residual sum of squares (absolute) & $4.73430880 \mathrm{E}-04$ \\
Standard error of the estimate & $9.73068220 \mathrm{E}-03$ \\
Coefficient of multiple determination $\left(R^{2}\right)$ & 0.99000557 \\
Multiple coefficient of determination $\left(R_{\mathrm{a}}^{2}\right)$ & 0.98240891 \\
\hline
\end{tabular}

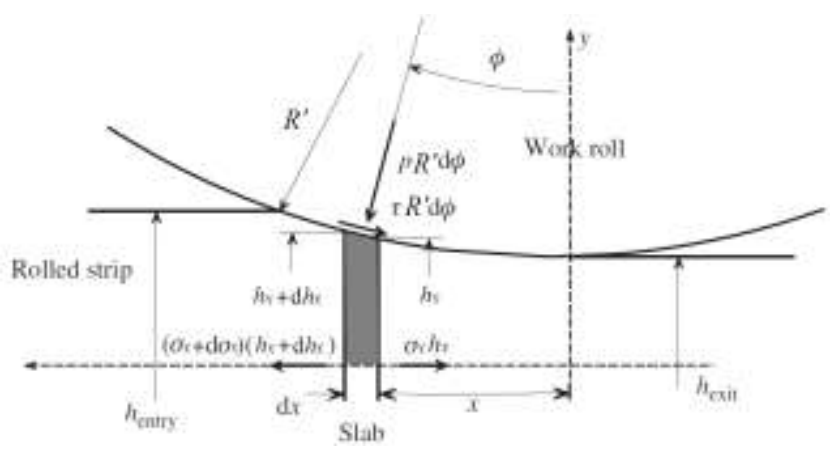

Fig. 12 Schematic diagram of forces acting on a slab of the deforming material, used in the model of Alexander ${ }^{[10]}$

describes the conditions of equilibrium in the backward slip zone (the negative sign) and in the forward slip zone (the positive sign). With the assumption of plane-strain plastic flow, the necessary additional equation is Eq. (10) based on the theory of Huber-Mises of plastic flow ${ }^{[11]}$.

$$
\sigma_{x}+p=2 K
$$

Another variable, $h_{x}$, can be obtained from the geometry of the deformation zone. Where $R^{\prime}$ is the radius of the flattened roller calculated by the theory of Hitcheock ${ }^{[10]}$.

$$
h_{x}=h_{\text {exit }}+2 R^{\prime}(1-\cos \phi) \approx h_{\text {exit }}+x^{2} / R^{\prime}
$$

Substituting Eq. (10) into Eq. (9) can get:

$$
\mathrm{d} p / \mathrm{d} x \pm 2 \mu p / h=2(k / h)(\mathrm{d} h / \mathrm{d} x)+\mathrm{d}(2 K) / d x
$$

\subsection{Friction effect on rolling force}

The effect of friction on rolling force was defined using shearing friction model (Eq. (13)) obtained from the theory of equivalent stress, considering that the friction is a part of the equivalent stress ${ }^{[12]}$. Where $\kappa(\kappa \leq 1)$ is a constant number, $\sigma_{\mathrm{f}}$ is frictional stress, $\bar{\sigma}$ is equivalent stress, $v_{\mathrm{r}}(\mathrm{mm} / \mathrm{s})$ is relative sliding speed, $v_{\mathrm{c}}(\mathrm{mm} / \mathrm{s})$ is critical speed when relative sliding happens, and $\mu$ is calculated by Eq.(8).

$$
\left\{\begin{array}{l}
P_{\sigma_{\mathrm{f}}}=\int_{0}^{L_{1}} \sigma_{\mathrm{f}} \frac{\sin \gamma}{\cos \gamma} \mathrm{d} x-\int_{L_{1}}^{L} \sigma_{\mathrm{f}} \frac{\sin \gamma}{\cos \gamma} \mathrm{d} x \\
\sigma_{\mathrm{f}}=-\kappa \mu \cdot \frac{\bar{\sigma}}{\sqrt{3}} \cdot \frac{2}{\pi} \arctan \left(\frac{v_{\mathrm{r}}}{v_{\mathrm{c}}}\right) \cdot \frac{v_{\mathrm{r}}}{\left|v_{\mathrm{c}}\right|} \\
v_{\mathrm{r}}=\left(v H / h_{x}\right) \sqrt{1+h_{x} / 4}-v
\end{array}\right.
$$

\subsection{Re-optimization of rolling force prediction model}

Combining Eq.(1) and Eq.(13), a prediction model for rolling force of magnesium alloy in hot rolling was obtained (Eq.(14)). Experimental values compared with the values calculated by Eq. (14) are shown in Fig. 13.

$$
P=\bar{p}_{1} B_{1} L_{c 1}+\bar{p}_{2} B_{2} L_{c 2}+\int_{0}^{L_{1}} \sigma_{\mathrm{f}} \frac{\sin \gamma}{\cos \gamma} \mathrm{d} x-\int_{L_{1}}^{L} \sigma_{\mathrm{f}} \frac{\sin \gamma}{\cos \gamma} \mathrm{d} x
$$




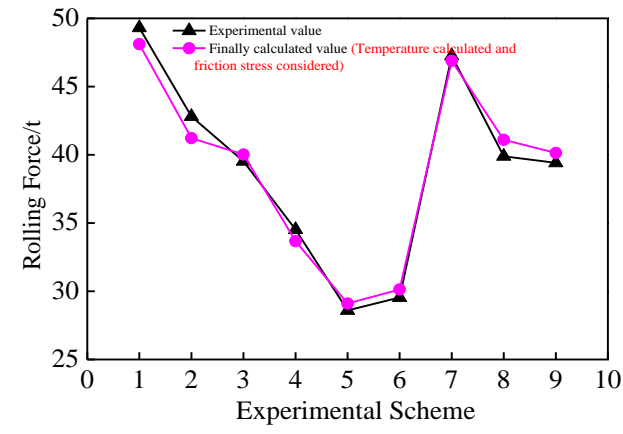

Fig. 13 Comparative analysis of calculated and experimental values

It is shown in Fig. 13, and compared with Eq. (1), the prediction accuracy of rolling force model after optimization and reconstruction is relatively higher. The main reason for small prediction error at the present stage is that the accuracy of the discrete solution for deformation mechanisms in deformation regions is not enough. The difference between the calculation of the Eq. (1) and Eq. (14) is the component of the friction effect on rolling force, which occupies approximately $4.36 \%$ of the total rolling force after the statistics.

\section{Conclusions}

1) Based on numerical simulation and physical experimental data, a method for the determination of the friction factor in rolling process is innovated, which avoids the high cost, low efficiency, and the high risk compared with the traditional measurement.

2) Through the accurate solution for unit normal pressure in deformation zone and quantitative study for the effect of contact friction, a rolling force prediction model with a higher precision is fitted and verified for AZ31B. The contact friction stress accounts for approximately $4.36 \%$ of the total rolling force.

\section{References}

1 Liu Z Y, Liu G, Liang S J. Rare Metal Materials and Engineering[J], 2007, 36(3): 304 (in Chinese)

2 Lenard J G, Barbulovic-Nad L. Journal of Tribology[J], 2002, 124(4): 840

3 Jia W T, Ma L F, Tang Y et al. Materials \& Design[J], 2016, 103: 171

4 Kang Yonglin. Rolling Engineering[M]. Beijing: Metallurgical Industry Press, 2004: 31 (in Chinese)

5 Ma L F, Jia W T, Lin J B et al. Rare Metal Materials and Engineering[J], 2016, 45(2): 339 (in Chinese)

6 Jia W T, Ma L F, Jiang Y P et al. Rare Metal Materials and Engineering[J], 2016, 45(3): 702 (in Chinese)

7 Zhu L, Li H, Wang W. The International Journal of Advanced Manufacturing Technology[J], 2013, 69(9): 2279

8 Jia W T, Ma L F, Ma Z Y et al. Rare Metal Materials and Engineering[J], 2016, 45(1): 152 (in Chinese)

9 Wang Tingfu, Qi Kemin. Metal Plastic Processing: Rolling Theory and Process[M]. Beijing: Metallurgical Industry Press, 2013: 31 (in Chinese)

10 Lenard J G. Primer on Flat Rolling[M]. Newnes, 2013: 75

11 Kwapisz M, Knapiński M, Dyja $\mathrm{H}$ et al. Archives of Metallurgy and Materials[J], 2015, 60(1): 149

12 Lenard J G. Primeron Flat Rolling, 2nd ed[M]. New York: Elsevier, 2014: 67

\title{
基于接触摩擦量化作用的镁合金轧制力预报研究
}

\author{
贾伟涛 ${ }^{1,2}$, 马立峰 ${ }^{1}$, 唐 岩 $^{2}$, 乐启炽 ${ }^{2}$, 黄志权 ${ }^{1}$, 林金宝 ${ }^{1}$ \\ (1. 太原科技大学 山西省冶金设备设计理论与技术重点实验室, 山西 太原 030024) \\ (2. 东北大学 材料电磁过程研究教育部重点实验室, 辽宁 沈阳 110819)
}

\begin{abstract}
摘 要: 针对镁合金热轧制工艺, 通过协调有限元分析结果及物理试验数据, 提出一种关于热轧制接触摩擦因子的确定方法, 耦合多 轧制工艺参数进一步拟合出其求解关系式，工艺参数包括：轧制温度，轧制速度以及压下率。在之前对 AZ31B 镁合金板材轧制过程轧 制力预报模型及温度场数学模型建立研究的基础上，综合考虑接触单位压力及摩擦应力两方面因素的作用，对前期轧制力预报模型进 行了优化重构, 经确定接触摩擦作用到轧辊的压力约占整体轧制力的 $4.36 \%$ 。
\end{abstract}

关键词: 轧制工艺; 摩擦系数; 轧制力; 法向压力; 摩擦应力

作者简介：贾伟涛, 男, 1986 年生, 博士生, 东北大学材料电磁过程研究教育部重点实验室 (EPM), 辽宁 沈阳 110819, E-mail: jwt860520@163.com 